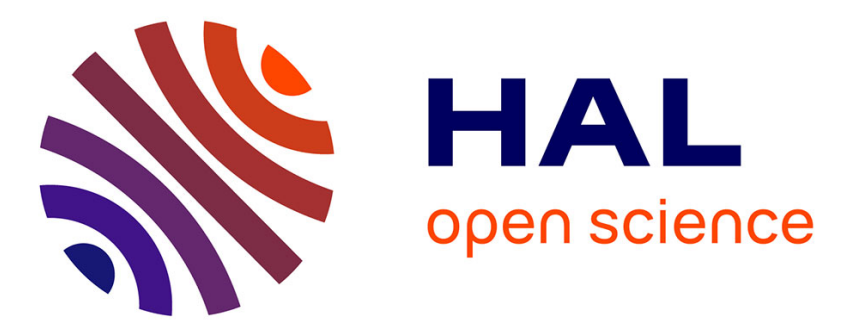

\title{
Ultra-smooth LiNbO3 micro and nano structures for photonic applications
}

G. Ulliac, B. Guichardaz, J.-Y. Rauch, S. Queste, S. Benchabane, N. Courjal

\section{To cite this version:}

G. Ulliac, B. Guichardaz, J.-Y. Rauch, S. Queste, S. Benchabane, et al.. Ultra-smooth LiNbO3 micro and nano structures for photonic applications. Microelectronic Engineering, 2011, 88 (8), pp.24172419. 10.1016/j.mee.2011.02.024 . hal-00583832

\section{HAL Id: hal-00583832 \\ https://hal.science/hal-00583832}

Submitted on 4 May 2021

HAL is a multi-disciplinary open access archive for the deposit and dissemination of scientific research documents, whether they are published or not. The documents may come from teaching and research institutions in France or abroad, or from public or private research centers.
L'archive ouverte pluridisciplinaire HAL, est destinée au dépôt et à la diffusion de documents scientifiques de niveau recherche, publiés ou non, émanant des établissements d'enseignement et de recherche français ou étrangers, des laboratoires publics ou privés. 


\title{
Ultra-smooth $\mathrm{LiNbO}_{3}$ micro and nano structures for photonic applications
}

\author{
Gwenn Ulliac*, Blandine Guichardaz, Jean-Yves Rauch, Samuel Queste, Sarah Benchabane, \\ Nadège Courjal
}

FEMTO-ST Institute, 18 rue Alain Savary, Besançon 25000, France

\begin{abstract}
We report on two approaches to achieve ultra-smooth structures on lithium niobate $\left(\mathrm{LiNbO}_{3}\right)$ substrates. The first method relies on ICP-RIE (inductively coupled-reactive ionic etching) or on RIE, and is exploited here for the fabrication of rods with smooth etched surfaces. A series of tests have been performed with fluorine gases. Nanometric rods with 200, 400 or $600 \mathrm{~nm}$ diameters, with a periodicity of 400,800 and $1200 \mathrm{~nm}$ respectively and etched angles close to $68^{\circ}$ for the RIE process and $75^{\circ}$ for the ICP-RIE process have been fabricated. The second process is based on "optical grade dicing" and is dedicated to the fab-rication of deep-etched ridge waveguides. First optical characterization results are reported. They show optical propagation losses value close to $0.1 \mathrm{~dB} / \mathrm{cm}$.
\end{abstract}

\section{Introduction}

Structuring $\mathrm{LiNbO}_{3}$ for photonic applications has been attracting much attention during the last 10 years owing to the potentialities offered by this material in terms of electro-optical, acousto-optical or nonlinear interactions and requires anisotropic etching for various devices. However, obtaining ultra-smooth structures with large aspect ratios is still a challenge that needs to be overcome if low optical losses are targeted. FIB (focused ion beam) milling has shown to be efficient for the fabrication of arrays of holes, and was successfully used for the development of electro-optical or acousto-optical micro-modulators [1,2]. However, the method is time-consuming and hence does not apply to the fabrication of rods or ridges. As an alternative, batch methods based on wet etching have been studied: many works have shown the capability of HF acids for etching $\mathrm{LiNbO}_{3}$ substrates [3-5]. Traditionally, these methods lead to rough etched surfaces, but recent developments have shown that it is possible to smooth wet-etched surfaces by a subsequent annealing at high temperatures $\left(\sim 1020^{\circ} \mathrm{C}\right)$. However, the annealing step causes an enlargement of the structures that seems incompatible with the fabrication of sub-micrometric rods. Techniques based on dry etching such as RIE, ICP-RIE, or NLD (neutral loop discharge) have also been proposed for the fabrication of photonic structures [6,7] or ridges [8]. But none of these publications report on the possibility to obtain ultra-smooth structures on lithium niobate substrates. In this paper, we present two methods which can lead to ultra-smooth $\mathrm{LiNbO}_{3}$ micro and nano structures

\footnotetext{
* Corresponding author.

E-mail address: gwenn.ulliac@femto-st.fr (G. Ulliac).
}

for photonic applications. The first method relies on dry etching techniques, and is used for the fabrication of nanometric rods with smooth etched surfaces. The second one is based on "optical grade dicing" and is dedicated to the fabrication of optical deep-etched ridge waveguides.

\section{Fabrication of nanometric rods with dry etching techniques}

We demonstrate here that nanometric rods surrounded with smoothed etch surfaces can be obtained by properly choosing the dry etching conditions, and by preliminarily realizing a proton exchange step (PE). The global process fabrication is schematically presented in Fig. 1. At first, a $\mathrm{LiNbO}_{3}$ substrate is dipped in a molten benzoic acid bath at $190{ }^{\circ} \mathrm{C}$ during $6.5 \mathrm{~h}$, in order to produce a significant lattice deformation, which will facilitate further etching. The replacement of $\mathrm{Li}^{+}$ions with $\mathrm{H}^{+}$protons helps to prevent from LiF redeposition during the dry etching step, which plays a role in both the verticality of the structures and the etch-rate. A PMMA positive resist is then spin-coated onto the substrate and patterned by electron-beam lithography (EBL) using an accelerate beam voltage of $30 \mathrm{kV}$. A $100 \mathrm{~nm} \mathrm{Cr}$ layer is then evaporated onto the substrate in order to improve the mask selectivity during the dry etching step. After the usual lift-off technique, the pattern is finally transferred to the substrate using fluorine based plasma-chemical etching processes. Optimization of etched depth, walls verticality, etch rate, etch selectivity towards the etch mask, and surface smoothness is investigated. The RIE etching is carried out using a Plassys reactor with a maximum power of $300 \mathrm{~W}$ and the ICP/RIE etching is carried out using a multiplex AOE reactor of STS with an ICP RF generator of $3 \mathrm{~kW}$ and a RIE generator of $1.5 \mathrm{~kW}$. The 


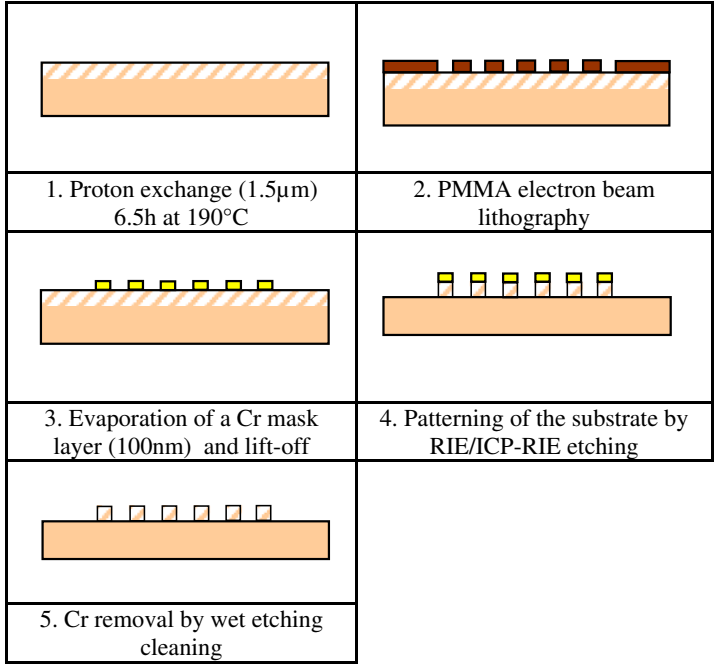

Fig. 1. Global flow-chart with the different process steps for nanometric rods fabrication.

(a)

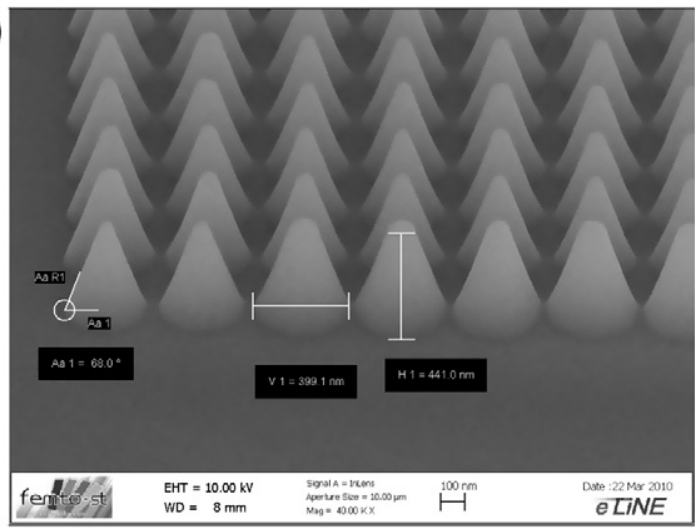

(b)

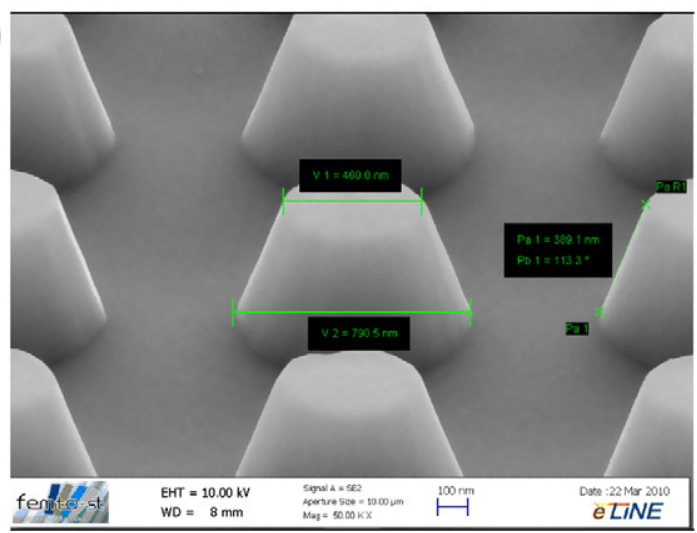

Fig. 2. SEM views of X-cut $\mathrm{LiNbO}_{3}$ substrates processed by proton exchange followed by RIE etching.

gas mixture used is $\mathrm{SF}_{6}$ for the RIE process and $\mathrm{CF}_{4} / \mathrm{He}$ for the ICPRIE process for $\mathrm{LiNbO}_{3}$ etch. At last, the remaining $\mathrm{Cr}$ mask layer is etched away using a wet etching solution.

The first results are shown in the SEM views of Figs. 2 and 3: it can be seen that the etched walls and surfaces exhibit a roughness lower than $10 \mathrm{~nm}$ (estimated by SEM observation), which allows the development of low loss photonic structures. A series of tests have been performed with fluorine gases to etch rods with 200, 400 or $600 \mathrm{~nm}$ diameters, and with a periodicity of 400,800 and (a)

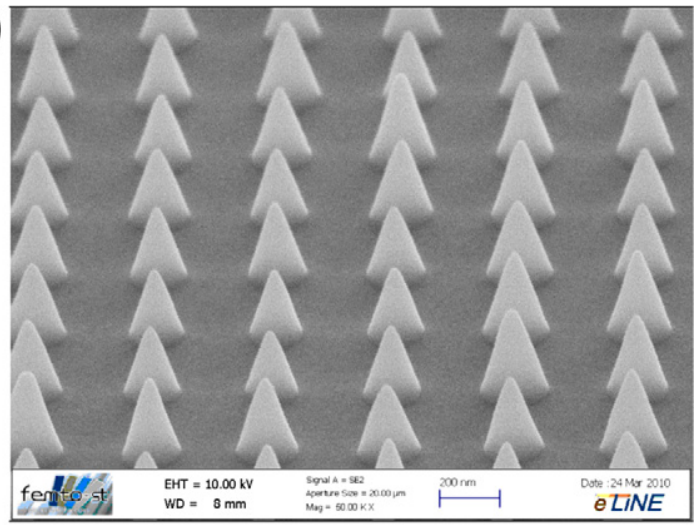

(b)

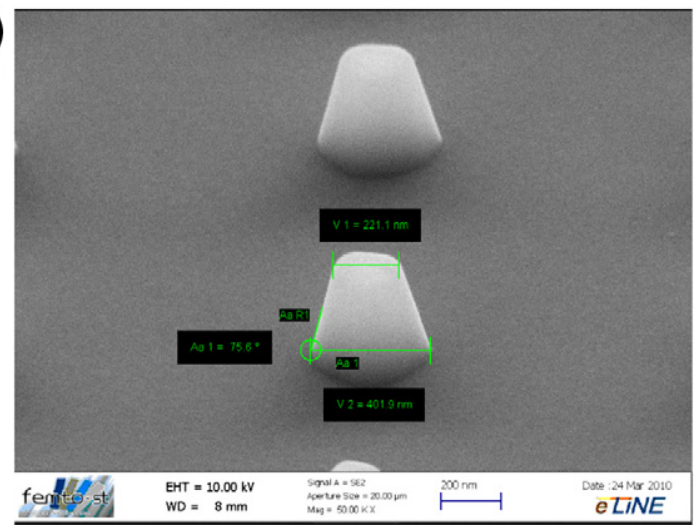

Fig. 3. SEM views of X-cut $\mathrm{LiNbO}_{3}$ substrates processed by proton exchange followed by ICP-RIE etching.

(a)

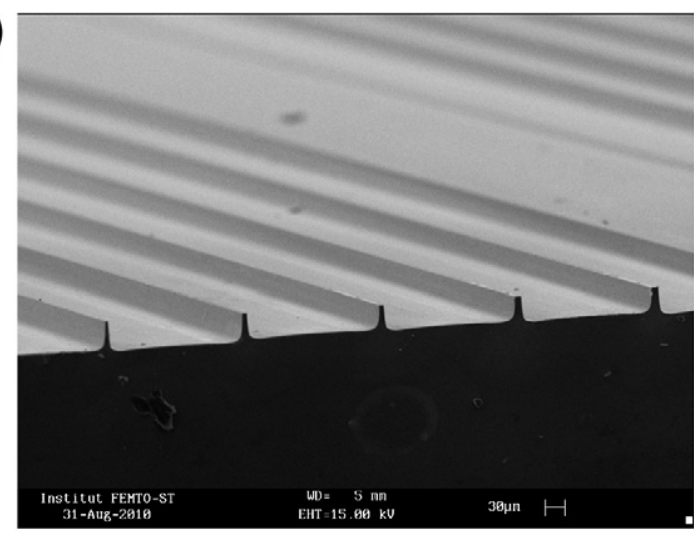

(b)

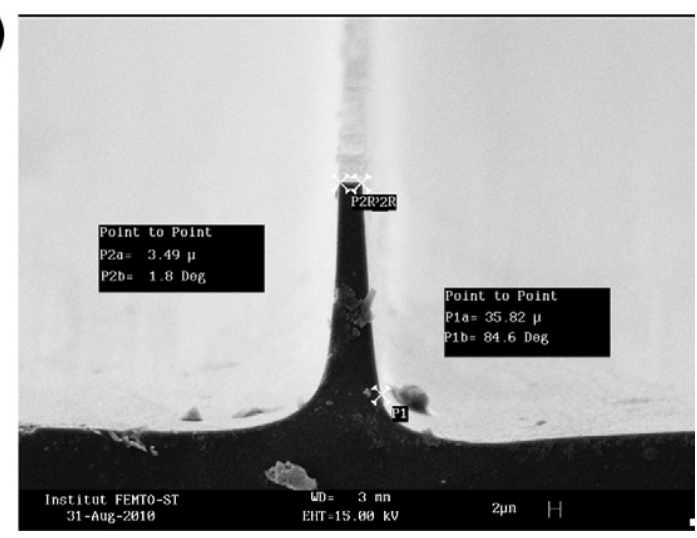

Fig. 4. SEM views of X-cut Ti:LiNbO 3 optical ridge waveguides fabricated by optical grade dicing. 
$1200 \mathrm{~nm}$ respectively. For the RIE process, the etched angles are measured to be $68^{\circ}$ with a $5: 1$ mask selectivity and an etch rate close to $90 \mathrm{~nm} \mathrm{mn}^{-1}$. For the ICP-RIE process, etched angles close to $75^{\circ}$, a $3: 1$ mask selectivity and an etch rate of $280 \mathrm{~nm} \mathrm{mn}^{-1}$ have been obtained.

\section{Fabrication of optical ridge waveguides with optical grade dicing method}

Concerning the fabrication of ridges, we propose an alternative method based on "optical grade dicing" which offers the great advantages of taking less than one hour of total process, while enabling a resolution of a few micrometers, an aspect ratio larger than 8 and smooth walls. This method consists in using a circular precision saw (DISCO DAD 441). More precisely, we propose to dice a sample on which a planar optical waveguide has been preliminarily implemented by a Ti-indiffused process: $\mathrm{Ti}: \mathrm{LiNbO}_{3}$ optical waveguide has been fabricated on a $0.5 \mathrm{~mm}$ thick X-cut Y-propagation $\mathrm{LiNbO}_{3}$ chip by standard diffusion of $80 \mathrm{~nm}$ thick titanium layer at $1020^{\circ} \mathrm{C}$ during $12 \mathrm{~h}$. These parameters are chosen in order to obtain the optical mode core close to the surface while keeping single mode propagation at $1.55 \mu \mathrm{m}$. The resulting straight grooves are separated with a few micrometers, and form the ridge waveguides. The speed of the blade is controlled in order to polish the substrate during the dicing step. In Fig. 4, we present SEM views of ridge waveguides with ultra-smooth side walls and vertical walls achieved with this method. Notably a $3.5 \mu \mathrm{m}$ large, $40 \mu \mathrm{m}$ deep and $1 \mathrm{~cm}$ long ridge is presented. First, a visualisation of the output mode is performed in order to get a quick overview of ridge waveguide behaviour. The vertical confinement of the optical monomode is "leak" and is linked to the index change due to the presence of titanium. But a high lateral confinement is obtained owing to an index difference higher than 1 between the $\mathrm{LiNbO}_{3}$ and surrounding air. Then, fibre to fibre measurements have been performed and optical propagation losses close to $0.1 \mathrm{~dB} / \mathrm{cm}$ have been experimentally obtained. This ridge is currently being processed by FIB milling to test its capacity to couple light into a photonic crystal cavity or Bragg gratings.

\section{Conclusions}

As a conclusion, original technological processes are proposed for the development of low loss $\mathrm{LiNbO}_{3}$ photonic structures. The first method relies on ICP-RIE or on RIE and opens the way for the production of densely integrated $\mathrm{LiNbO}_{3}$ photonic crystalbased devices over large areas. The second one based on "optical grade dicing" is an alternative method for the fabrication of low loss optical waveguides.

\section{References}

[1] M. Roussey, M.-P. Bernal, N. Courjal, F.I. Baida, R. Salut, Appl. Phys. Lett. 89 (2006) 241110.

[2] N. Courjal, S. Benchabane, J. Dahdah, G. Ulliac, Y. Gruson, V. Laude, Appl. Phys. Lett. 96 (2010).

[3] I.E. Barry, G.W. Ross, P.G.R. Smith, R.W. Eason, G. Cook, Mater. Lett. 37 (1998) 246

[4] V. Dobrusin, S. Rushin, L. Shpisman, Opt. Mater. 29 (2007) 1630-1634.

[5] H. Hu, R. Ricken, W. Sohler, Appl. Phys. B 98 (2010) 677-679.

[6] G. Ulliac, N. Courjal, H.M.H. Chong, R.M. De La Rue, Opt. Mater. 31 (2008) 196200.

[7] Z. Ren, P.J. Heard, J.M. Marshall, P.A. Thomas, S. Yu, J. Appl. Phys. 103 (2008) 034109.

[8] W.S. Yang, H.Y. Lee, W.K. Kim, D.H. Yoon, Opt. Mater. 27 (2005) 1642-1646. 